\title{
A Substituição de Trabalhadores como Instrumento para Redução de Gastos com Salários: Evidências para a Indústria Paulista
}

\author{
Veronica Orellano*, Enlinson Mattos ${ }^{\dagger}$, Elaine Pazello
}

\begin{abstract}
Contents: 1. Introdução; 2. 0 Modelo; 3. Medindo a substituição de empregados por iniciativa da firma; 4. Os Dados; 5. O Modelo Econométrico e os Resultados Obtidos; 6. Conclusões.
\end{abstract}

Keywords: Labor Turnover; Labor Churning; Wage Costs.

JEL Code: J63, J31, H32.

O movimento de substituição de trabalhadores por parte das firmas - aqui tratado como churning - é um importante componente da rotatividade da mão-de-obra no Brasil, que também inclui a realocação de emprego entre firmas. A evolução do labor churning ao longo da década de 1990, ao menos para os empregados formais da indústria paulista, segue uma trajetória muito semelhante para as diferentes faixas de tamanho de firmas e para os diferentes subsetores da indústria, sugerindo que mudanças no ambiente macroeconômico afetam o churning de forma similar em firmas com características diferentes. Este artigo propõe um modelo para explicar o movimento de labor churning dos empregados formais no país. O modelo admite que as firmas, ao enfrentarem choques exógenos que elevam o salário real, podem substituir empregados com o objetivo de reduzir seus gastos com salários, particularmente em momentos de baixa inflação, em que há maior rigidez dos salários reais. Um estudo econométrico é realizado a partir dos microdados da RAIS (Relação Anual de Informações Sociais, do Ministério do Trabalho) para o setor industrial da Região Metropolitana de São Paulo. Os resultados obtidos corroboram a hipótese do modelo. As estimações ainda sugerem que, no período pós-plano real, controlada a inflação e quando os instrumentos são válidos, o churning da mão-de-obra foi relativamente maior que no início da década de 1990. Labor churning is an important component of labor turnover in Brazil, which includes job reallocation between firms. The labor churning evolution in the nineties, at least for the

\footnotetext{
*Escola de Economia de São Paulo, Fundação Getúlio Vargas. Rua Itapeva, 474, CEP: 01332-000, Bela Vista, São Paulo - SP. E-mail: veronica.orellano@fgv.br

${ }^{\dagger}$ Escola de Economia de São Paulo, Fundação Getúlio Vargas. E-mail: enlinson.mattos@fgv.br

${ }^{\ddagger}$ Departamento de Economia da FEA Ribeirão Preto, Universidade de São Paulo. E-mail: epazello@usp.br
} 
industry sector in São Paulo, folows a very similar path for different groups of firms (divided by size or by subsectors), suggesting that changes in the macroeconomic environment affect labor churning in a very similar way for different firms. This paper proposes a model to explain the path offormal labor churning in Brazil. The model admits that employers, when facing exogenous shocks that rise real wage, may substitute employees to reduce wage costs, particularly in low inflation periods, when real wages are more rigid. An econometric analysis is conducted using disaggregated data by firms for the industry sector in the Metropolitan Region of São Paulo. The results confirm the model's main hypothesis. The results also suggest that, after the monetary estabilization, controlling for inflation and with valid instruments, labor churning is relatively higher.

\section{INTRODUÇÃO}

A elevada rotatividade da mão-de-obra é uma característica marcante do mercado de trabalho brasileiro. ${ }^{1}$ Além disso, os dados mostram que o labor churning é um importante componente do movimento total de rotatividade da mão-de-obra formal no Brasil, o qual também inclui a realocação de emprego formal entre firmas. O labor churning corresponde àquela parcela da rotatividade que diz respeito apenas ao movimento de substituição de trabalhadores por parte de cada firma, que pode ocorrer mesmo que todas as firmas mantenham inalterado o seu nível de emprego. Os Dados da Relação Anual de Informações Sociais revelam que, para os empregados formais da indústria paulista na década de 1990, o labor churning foi responsável por mais da metade do movimento total de rotatividade da mão-de-obra.

A teoria econômica explica o labor churning com base em modelos de demissões voluntárias ou de matching. Quando ocorrem demissões voluntárias, a firma em geral é obrigada a contratar novos funcionários, arcando com os custos de transação desse processo. As demissões voluntárias ocorrem sobretudo em momentos de aquecimento da economia e baixo desemprego, provocando uma relação inversa entre churning e desemprego. ${ }^{2}$ Já os modelos de matching explicam o labor churning por teorias de revelação de produtividade ex post (sobre isso ver Burgess et al. (2000)). Num ambiente de informação assimétrica a respeito da produtividade do trabalhador, a firma precisa contratar o trabalhador para conhecer a sua produtividade; se esta for menor que a esperada, a firma irá substituí-lo. ${ }^{3}$

As evidências empíricas sobre labor churning no Brasil sugerem fortemente que as teorias mais conhecidas sobre esse tema têm baixo poder para explicar tanto o nível quanto a evolução do labor churning nesse país. A correlação negativa entre desemprego e labor churning, prevista pela correlação negativa esperada entre desemprego e demissões voluntárias, é identificada neste estudo. Contudo,

\footnotetext{
${ }^{1}$ Vários autores brasileiros, como Amadeo et al. (1993), Cacciamali (1992), Gonzaga (1996), Corseuil et al. (2002b) e Gonzaga (2003), apresentam evidências a esse respeito.

${ }^{2}$ É possível identificar pelo menos três grupos de modelos teóricos que tratam da relação entre demissões voluntárias e rotatividade da mão-de-obra:

(i) on-the-job search models, como em Barron and McCafferty (1977) e (Ehrenberg and Smith, 2000, cap. 10);

(ii) the labor turnover efficiency wage model, sendo Stiglitz (1974) e Salop (1979) os primeiros autores a desenvolvê-lo; e

(iii) modelos de economia institucional, como em (Williamson, 1985, p. 245-247).
}

\footnotetext{
${ }^{3}$ Neste ponto cabe ressaltar que os modelos dinâmicos de demanda por trabalho (dynamic models of labour demand), como os de Nickell $(1978,1986,1995)$, apesar de tratarem das decisões de demissão e contratação de empregados por parte das firmas, não podem ser incluídos entre os modelos que tratam do labor churning. Esses modelos dinâmicos estudam a resposta das firmas, em termos de demanda por trabalho, às oscilações na demanda pelo produto.
} 
essa correlação não explica satisfatoriamente o padrão observado de evolução do churning ao longo do tempo, o qual é muito semelhante entre os diferentes setores da indústria e entre diferentes grupos de tamanho de firmas. ${ }^{4}$

A partir das características do mercado de trabalho brasileiro, este artigo propõe um modelo para explicar o movimento de labor churning dos empregados formais no país, focalizando a atenção na substituição de trabalhadores que ocorre por iniciativa das firmas, e não como consequência de demissões voluntárias. Dadas as características específicas do mercado de trabalho brasileiro e suas instituições, a idéia de labor churning provocado pelas firmas - que seria a princípio contraditória - poderia ser explicada a partir da racionalidade econômica dos empregadores.

Os modelos de matching admitem que as firmas substituem empregados quando a produtividade destes (observada após a contratação) é menor do que a esperada. Caso contrário, a substituição de empregados apenas aumentaria o custo das firmas, dados os conhecidos custos de transação envolvidos tanto nos processos de demissão quanto de contratação. Porém os modelos de matching não são capazes de explicar as oscilações do labor churning observadas na indústria no Brasil.

No mercado de trabalho brasileiro, que é segmentado entre mercado formal e informal, a porcentagem de empregados sem registro formal é maior que 0,4 . Os empregados formais têm direito a uma série de benefícios aos quais os empregados informais não têm acesso. Ademais, diversos estudos concluem que, além desses benefícios, os empregados formais ganham salários maiores em média do que os informais (controladas as demais caracteristicas relevantes). ${ }^{5}$

O modelo proposto admite a possibilidade das firmas substituirem empregados formais com o objetivo de reduzir o salário pago a seus empregados, quando enfrentam choques exógenos que elevam o salário real - particularmente nos momentos de baixa inflação, em que há maior rigidez dos salários reais. Apresenta-se então uma análise econométrica usando dados de painel que corrobora a idéia principal do modelo. Esta foi realizada a partir dos microdados da RAIS (Relação Anual de Informações Sociais, do Ministério do Trabalho) para o setor industrial da Região Metropolitana de São Paulo.

Este artigo está dividido em 5 seções, além desta introdução. A segunda seção apresenta o modelo teórico. A terceira explica a medida de labor churning calculada para cada firma e a seção seguinte descreve os dados. Por fim apresenta-se o modelo econométrico e seus resultados e, na última seção, as conclusões.

\section{O MODELO}

Considere uma economia com trabalhadores com habilidades idênticas e duas firmas que produzem bens distintos, utilizando apenas mão de obra como insumo, descritas abaixo.

$$
\begin{aligned}
& Y_{t}^{1}=F\left(L_{t}^{1}\right) \\
& Y_{t}^{2}=G\left(L_{t}^{2}\right)
\end{aligned}
$$

onde $Y_{t}^{i}$ corresponde ao produto da firma $i=1,2$ no tempo $t$ e $F($.$) e G($.$) são duas funções côncavas.$ Assuma ainda que apenas uma destas duas firmas esteja coberta pela legislação desta economia. Esta legislação garante o salário mínimo e outros benefícios. ${ }^{6}$ Desta forma, podemos escrever a equação de lucro desta firma da seguinte forma:

\footnotetext{
${ }^{4}$ Ver Figuras 2 e 3 comentadas na seção 4.

${ }^{5}$ Sobre o assunto ver, por exemplo, Ulyssea (2006) e Botelho and Ponczek (2007).

${ }^{6}$ Observe que como apenas um setor está regulamentado, ocorrem distorções na economia podendo fazer com que a firma sob legislação contrate menos trabalhadores do que contrataria em caso contrário, gerando distorções nos tamanhos das firmas. No entanto, apenas estamos interessados em decisões das empresas após esta implementação.
} 


$$
\Pi_{t}^{1}=P_{t}^{1} F\left(L_{t}^{1}\right)-\left[w_{0}+B_{t, T}\right] L_{t}^{1}
$$

onde $\left(P_{t}^{1}, w_{0}, B_{t, T}\right)$ correspondem ao preço do produto da firma 1 no período $t$, ao salário de equilíbrio da economia na ausência de regulamentação do mercado de trabalho e o último termo denota os benefícios que devem ser pagos em $t$ ao trabalhador com tempo $T$ de permanência na firma. Assim sendo, a equação que descreve o lucro das firmas nada mais é que a diferença entre a receita e o custo. Podemos ainda escrever o elemento $B_{t, T}$,

$$
B_{t, T}=\left[\overline{x_{t}}-w_{0}\right]+b_{t, T}\left(T, \overline{x_{t}}\right)
$$

onde o primeiro componente descreve o diferencial de salários entre o salário de equilíbrio na ausência de regulamentação do trabalho e o salário imposto pela legislação $\left(\bar{x}_{t}\right)$ e o segundo elemento se refere aos demais benefícios: tanto aqueles impostos por lei (como as contribuições ao INSS e ao FGTS), quanto aqueles decorrentes da política salarial da firma de ganhos por tempo de serviço $(T)$. Assumimos que a variável $b_{t, T}$ é afetada positivamente por $T$ e $\overline{x_{t}}$.

Já para a firma 2 temos a seguinte função lucro em cada período,

$$
\Pi_{t}^{2}=P_{t}^{2} G\left(L_{t}^{2}\right)-\left[w_{0}\right] L_{t}^{2}
$$

Antes de desenvolver a solução do modelo é preciso fazer duas considerações. A primeira é que, neste modelo, a melhor opção para os trabalhadores é estar na firma regulamentada, pois teriam salários maiores e também outros benefícios. Então, se eventualmente abrisse uma vaga no setor regulamentado, todos os trabalhadores da economia teriam interesse em preenchê-la. A segunda é que assumimos que o setor regulamentado abriga um número menor ou igual de trabalhadores quando comparado ao setor não regulamentado, ou seja, $L_{t}^{1} \leq L_{t}^{2}{ }^{7}$ Isto pode ser obtido se impusermos que a função de produção dos dois setores é similar e, consequentemente, com custos marginais maiores teremos um número menor de trabalhadores na firma 1. Desta forma, diante da possibilidade de rotatividade da mão de obra, todos os trabalhadores da firma 2 têm probabilidade idêntica de obter um emprego regulamentado, assim como todos os trabalhadores com tempo de permanência similar na firma regulamentada têm probabilidade positiva de sair da mesma. ${ }^{8}$

Para resolver este modelo, é necessário dividí-lo em duas etapas. Primeiro diagnosticamos qual o problema das firmas em cada instante no tempo. Esta etapa é relevante pois aponta para a possibilidade das firmas efetuarem a política de rotatividade dos trabalhadores em contrapartida à elevação de custos regulamentados (salário mínimo, benefícios etc.) ou cíclicos (valorização da taxa de câmbio, por exemplo). Na segunda etapa, apresentamos a decisão do tamanho ótimo das firmas no longo prazo, levando em consideração as decisões instantâneas.

Define-se então $C^{r}$ como o custo de reposição da mão de obra atual pela "mais barata", ou seja, o custo da rotatividade. Este custo busca capturar os gastos inerentes ao processo de demissão dos atuais e contratação dos novos funcionários.

Em cada instante do tempo a firma 1 depara-se com a seguinte decisão. Dadas as condições de mercado, pode optar por trocar todos os trabalhadores ou manter os atuais funcionários. Para isto tem que comparar o custo marginal trazido a valor presente de manter o último funcionário com o custo de despedi-lo. Se o último custo for maior, a firma 1 decide então "trocar" o funcionário. A equação abaixo ilustra o processo de decisão.

\footnotetext{
${ }^{7}$ Lembre-se que o setor 1 tem a demanda por trabalho racionada com a imposição de custos regulamentados, enquanto que o outro setor pode receber quantos trabalhadores forem necessários uma vez que o ajuste se dê pelo salário de equilíbrio $\left(w_{0}\right)$.

${ }^{8}$ Para maiores detalhes a respeito de probabilidade racionada, ver Mincer (1976).
} 


$$
\begin{aligned}
\frac{\sum_{t=0}^{\infty} E\left[\left(\bar{x}_{t}\right]\right.}{(1+r)^{t}}+\frac{\sum_{t}^{\infty} E\left[b_{t, T} / C^{r} \neq 0, T=0\right]}{(1+r)^{t}} & +\frac{C^{r}}{\sum_{t=0}^{\infty}(1+r)^{t}} \\
& \leq \frac{\sum_{t=0}^{\infty} E\left[\left(\overline{x_{t}}\right)\right]}{(1+r)^{t}}+\frac{\sum_{t}^{\infty} E\left[b_{t, T} / C^{r}=0, T \neq 0\right]}{(1+r)^{t}}
\end{aligned}
$$

O lado esquerdo da equação se refere ao custo marginal de substituir um funcionário da firma 1 . 0 primeiro termo é o valor presente do salário regulamentado a ser pago, o segundo termo contabiliza os benefícios futuros esperados trazidos a valor presente, dado que a firma decidiu fazer a substituição e o último termo corresponde ao custo fixo de reposição. Já o lado direito apresenta também o salário regulamentado a ser recebido pelo funcionário "antigo", juntamente com seus benefícios esperados trazidos a valor presente. $\mathrm{O}$ fato de usarmos as esperanças condicionais dos benefícios nas diferentes situações deixa claro que, diante de uma mudança nas condições de mercado, a política de ganhos por tempo de serviço pode mudar para os novos contratados. Contudo, os ganhos já concedidos a um trabalhador não podem ser retirados. Um exemplo seria o de firmas que tenham concedido promoções salariais fixadas em salários mínimos, de tal maneira que quem estava na firma a um ano passaria a ganhar, por exemplo, 1.5 vezes o salário mínimo). ${ }^{9}$ Outro exemplo seria a concessão de um plano de saúde após um ano de permanência na firma. Esse benefício, uma vez concedido, não poderia ser retirado. Se ocorre, por exemplo, um aumento inesperado no valor real do salário mínimo, necessariamente aumenta o custo da firma com mão-de-obra. No caso de promoções salariais fixadas com base no salário mínimo, o salário dos veteranos aumentaria na mesma proporção que o dos iniciantes. Já no exemplo da concessão de um plano de saúde, o inevitável aumento dos salários não poderia ser compensado com a retirada do benefício. Em ambos os exemplos, claramente aumenta o valor presente do total de benefícios a serem pagos aos trabalhadores se estes permanecerem na firma.

Quando o lado esquerdo for inferior ao lado direito da equação 5, então compensa para a empresa efetuar a política de rotatividade no período $t$. Ou seja, a política de substituição dos trabalhadores ocorre quando a expectativa de beneficios futuros a serem pagos ao funcionário antigo superar o custo fixo de reposição deste funcionário juntamente com a evolução esperada dos benefícios do novo empregado. Caso contrário, a melhor opção é manter o funcionário por mais um período.

No que diz respeito ao tamanho ótimo das firmas para o longo prazo, temos que o lucro da firma 1 é maximizado quando o custo marginal de contratar um trabalhador for idêntico ao produto marginal deste trabalhador. Em particular, quando o custo de efetuar a rotatividade for inferior, esta equação de equilíbrio se torna, ${ }^{10}$

$$
\sum_{t=0}^{\infty} \frac{P_{t}^{1} F^{\prime}\left(L_{t}^{1}\right)}{(1+r)^{t}}=\frac{\sum_{t=0}^{\infty} E\left[\left(\overline{x_{t}}\right)\right]}{(1+r)^{t}}+\frac{\sum_{t=0}^{\infty} E\left[b_{t, 0} / C^{r} \neq 0, T \neq 0\right]}{(1+r)^{t}}+\frac{C^{r}}{\sum_{t=0}^{\infty}(1+r)^{t}}
$$

A firma 1, neste caso, optaria por efetuar a política de rotatividade em todo o instante de tempo, uma vez que seu custo é inferior ao custo de manter o funcionário na empresa devido a expectativa da evolução dos benefícios futuros. Por isso o termo $b_{t, 0}$ descreve que não há alteração na permanência dos funcionários da empresa 1 além do primeiro período. ${ }^{11}$ Caso contrário a condição de equilíbrio se

\footnotetext{
${ }^{9} \mathrm{~A}$ idéia que está por trás desse exemplo é o uso do salário mínimo como numerário, fenômeno não raro denominado de efeito numerário. Camargo et al. (2001) destacam a existência desse efeito no mercado formal de trabalho no Brasil.

${ }^{10}$ Este problema ainda pode ser escrito como programação dinâmica, onde a firma do setor formal escolhe a cada momento do tempo, seu tamanho $\left(L_{t}^{1}\right)$ e a política de beneficios do período seguinte $\left(b_{t+1}\right)$ que incluiria o custo de reposição, $C^{r}$, porém optou-se por apresentar o problema desta forma mais simples.

${ }^{11}$ Lembre que isto só pode ocorrer porque o número de trabalhadores na firma 2 é suficiente para esta substituição de trabalhadores. Ainda, estes trabalahdores estão dispostos a trabalhar neste setor, pois terão um rendimento maior.
} 
torna,

$$
\sum_{t=0}^{\infty} \frac{P_{t}^{1} F^{\prime}\left(L_{t}^{1}\right)}{(1+r)^{t}}=\frac{\sum_{t=0}^{\infty} E\left[\left(\bar{x}_{t}\right)\right]}{(1+r)^{t}}+\frac{\sum_{t)=0}^{\infty)} E\left[b_{t, T} / C^{r}=0, T=0\right]}{(1+r)^{t}}
$$

Isto implica que esta decisão também afeta o tamanho relativo da firma 1 , pois o $L^{1}$ é diferente para os dois casos. Já para a firma 2 temos,

$$
\sum_{t=0}^{\infty} \frac{P_{t}^{2} G^{\prime}\left(L_{t}^{2}\right)}{(1+r)^{t}}=w_{0} \sum_{t=0}^{\infty}(1+r)^{-t}
$$

Esta equação, por sua vez, determina o tamanho ótimo da firma 2, ou seja, esta contrata trabalhadorers até que a produtividade marginal do último trabalhador, trazida à valor presente, se iguale ao custo marginal.

O modelo desenvolvido nesta seção busca explicar quais fatores podem influenciar a decisão das firmas para que optem por implementar a política de rotatividade. Os fatores que podem implicar esta implementação afetam diretamente a expectativa quanto à evolução da variável $b_{t, T}$ : como por exemplo um aumento do salário mínimo. Outro exemplo seria uma valorização cambial para os exportadores que causasse um aumento do salário real. Como será visto mais adiante, utilizamos variações destas variáveis como instrumentos para a variação do salário real, pois estas podem afetar diretamente as expectativas das firmas quanto a evolução dos benefícios.

\section{MEDINDO A SUBSTITUIÇÃO DE EMPREGADOS POR INICIATIVA DA FIRMA}

A rotatividade da mão-de-obra da firma $i$ no período de tempo $t$ pode ser medida pelo cálculo da seguinte razão:

$$
R_{i t}=\frac{\min \left(a_{i t}, d_{i t}\right)}{\left(L c_{i t}+L f_{i t}\right) / 2}
$$

em que $a_{i t}$ corresponde ao número de admissões ocorridas na firma $i$ no período $t, d_{i t}$ corresponde ao número de desligamentos ocorridos na firma $i$ no período $t, L c_{i t}$ corresponde ao total da força de trabalho da firma $i$ no começo do período $t$ e $L f_{i t}$ corresponde ao total da força de trabalho da firma $i$ no final do período $t$. Logo, $\left(L c_{i t}+L f_{i t}\right) / 2$ corresponde ao número médio de empregados da firma $i$ no período $t$.

Adotando-se essa definição, aumentos ou quedas da força de trabalho da firma no período $t$ não são contabilizados como rotatividade. Leva-se em consideração apenas aquela quantidade de mão-de-obra que foi substituída. Portanto, o conceito subjacente a esse índice de rotatividade da mão-de-obra é o movimento de entrada e saída de trabalhadores da firma, enquanto esta mantém a sua força de trabalho. Além disso, vale ressaltar que a escolha do período de tempo em que o índice de rotatividade da mãode-obra é calculado tem implicações sobre o resultado obtido. Se o período de tempo considerado for muito curto, variações sazonais da demanda por trabalho da firma não são contabilizadas como rotatividade. Neste artigo usamos muitas vezes o termo churning da firma $i$ para nos referirmos ao índice $R_{i t}$. Adota-se essa nomenclatura porque o conceito de churning da mão-de-obra da economia é difundido na literatura internacional. A taxa de churning da mão-de-obra de uma economia no período $t$, conforme definida em Davis et al. (1998), é igual ao dobro da média ponderada dos índices $R_{i t}$, sendo a ponderação feita pelo número médio de empregados de cada firma em $t .^{12}$

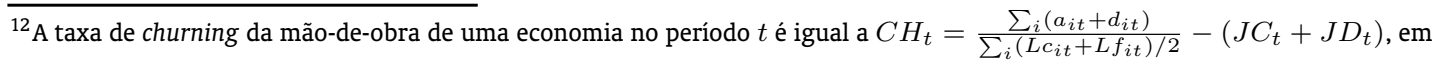
que $J C_{t}$ é a taxa de criação total de emprego da economia em $t$ e $J D_{t}$ é a taxa de destruição total de emprego da economia em $t$, conforme definidas em Davis et al. (1998). Para detalhes a respeito da relação entre $C H_{t}$ e $R_{i t}$, ver Orellano and Pazello (2006).
} 
Este estudo, porém, focaliza a atenção na substituição de trabalhadores que ocorre por iniciativa das firmas, e não como consequência das demissões voluntárias. Sendo assim, definimos uma taxa de rotatividade involuntária da mão-de-obra da firma $i$ em $t$, que é igual a:

$$
R I_{i t}=\frac{\min \left(a_{i t}, d i_{i t}\right)}{\left(L c_{i t}+L f_{i t}\right) / 2}
$$

em que $a_{i t}$ corresponde ao número de admissões ocorridas na firma $i$ no período $t, d i_{i t}$ corresponde ao número de demissões involuntárias (por iniciativa da firma) ocorridas na firma $i$ no período $t$, e $\left(L c_{i t}+L f_{i t}\right) / 2$ corresponde ao número médio de empregados da firma $i$ no período $t$. Neste trabalho usaremos muitas vezes o termo churning involuntário da firma $i$ em $t$ para nos referirmos ao índice $R I_{i t}$.

Por fim, uma vez que este estudo visa a analisar o comportamento das firmas de substituir empregados com o objetivo de reduzir salários, optou-se pelo uso de um indicador que extrai do índice $R I_{i t}$, definido acima, aquela parcela decorrente de uma possível necessidade das firmas de alterar o perfil de seus empregados em termos de nível de qualificação. Se ocorre uma mudança na tecnologia de produção, isso pode gerar a necessidade de substituição de alguns empregados por outros com diferente qualificação, afetando-se a rotatividade involuntária (e o índice $R I_{i t}$ ) em cada firma. A causa desse comportamento, contudo, é bem diferente do objetivo de redução do salário real discutido no modelo proposto na seção anterior.

Orellano and Pazello (2006) apresentam uma medida de churning da firma que desconsidera aquela parcela da substituição de trabalhadores que altera o perfil de qualificação destes - como por exemplo a substituição de trabalhadores braçais menos qualificados por trabalhadores com maior escolaridade. Esse movimento, em geral decorrente de avanço tecnológico, é extraído do indicador usado.

Para construir esse indicador é preciso medir primeiro o movimento de troca de trabalhadores com um certo nível de qualificação por outros com diferente nível. Para tanto, calcula-se em primeiro lugar a soma das criações de emprego ocorridas nas diferentes faixas de qualificação para cada firma $\left(C F Q_{i t}\right)$; e a soma das destruições de emprego ocorridas nas diferentes faixas de qualificação para cada firma $\left(D F Q_{i t}\right)$.

Um exemplo simples, com apenas três faixas de qualificação, auxilia a compreensão da medida a ser usada. Considere uma firma que tem 100 empregados no início do período. As contratações e desligamentos por iniciativa da firma ocorridos no período estão apresentados na tabela 1.

Table 1: Exemplo

\begin{tabular}{|c|c|c|c|}
\hline & Faixa de qualific. 1 & Faixa de qualif. 2 & Faixa de qualif. 3 \\
\hline Contratações & 20 & 10 & 25 \\
\hline Desligamentos & 30 & 12 & 15 \\
\hline Criação & 0 & 0 & 0 \\
\hline Destruição & 10 & 2 & 0 \\
\hline
\end{tabular}

Para essa firma hipotética nesse período, a soma das criações de emprego ocorridas nas diferentes faixas de qualificação $\left(C F Q_{i t}\right)$ é 10 e a soma das destruições de emprego ocorridas nas diferentes faixas de qualificação $\left(D F Q_{i t}\right)$ é 12. Logo o mínimo entre $C F Q_{i t}$ e $D F Q_{i t}$ é 10. Dividindo esse valor mínimo pelo número médio de empregados da firma no período, obtemos uma taxa de 10/99, que é igual a aproximadamente 0,1 , ou 10 por cento. Essa taxa é uma medida do quanto a firma alterou o perfil de seus empregados em termos de nível de qualificação. Uma parte do churning de uma firma pode ter essa função. Contudo, é perfeitamente possível que uma firma com elevada taxa de churning não altere em nada o perfil de qualificação de seus funcionários. 
Para extrair do índice $R I_{i t}$ aquela parcela de substituições que altera o perfil dos empregados em termos de nível de qualificação, a seguinte medida é proposta:

$$
R I L_{i t}= \begin{cases}R I_{i t}-\min \left(C F Q_{i t}, D F Q_{i t}\right) & \text { se } R I_{i t}-\min \left(C F Q_{i t}, D F Q_{i t}\right)>0 \\ 0 & \text { se } R I_{i t}-\min \left(C F Q_{i t}, D F Q_{i t}\right) \leq 0\end{cases}
$$

Na equação 11 fica claro que o cálculo da diferença $R I_{i t}-\min \left(C F Q_{i t}, D F Q_{i t}\right)$ pode gerar valores negativos. Isso acontece porque a destruição de emprego não ocorre apenas via demissões por iniciativa das firmas, mas também via demissões voluntárias, aposentadorias, ou mesmo mortes. Com isso, uma firma que apresentou $R I L_{i t}=0$ poderia ter alterado o perfil de qualificação dos seus empregados, o que resultaria num valor negativo para $R I_{i t}-\min \left(C F Q_{i t}, D F Q_{i t}\right)$. Nesses casos atribui-se o valor 0 para $R I L_{i t}$.

Neste trabalho usaremos muitas vezes o termo churning involuntário líquido da firma $i$ em $t$ para nos referirmos ao índice $R I L_{i t}$.

\section{OS DADOS}

Neste trabalho foram utilizados os dados da RAIS (Relação Anual de Informações Sociais do Ministério do Trabalho), para o setor industrial, desagregados por firma (microdados). A raiz do Cadastro Nacional da Pessoa Jurídica (CNPJ) (números antes da barra) foi usada para identificar cada firma. Essas informações dizem respeito ao total de empregados com carteira de trabalho assinada, incluindo funcionários públicos. Porém neste estudo foram considerados apenas os trabalhadores com contrato de trabalho regido pela Consolidação das Leis do Trabalho (CLT). O período de tempo escolhido para o cálculo dos índices de rotatividade apresentados na seção anterior foi de um ano. Assim sendo, oscilações da demanda por trabalho de cada firma ocorridas dentro do intervalo de um ano são contabilizadas como churning da mão-de-obra das firmas.

Foi possível obter os microdados para os anos de 1990 até 1998. Porém, para o cálculo dos índices de rotatividade apresentados na seção anterior, é necessário saber o nível médio de emprego de cada firma em cada ano. Por isso os índices de rotatividade foram calculados para o período 1991-1998.

Foram realizados dois ajustes para o cálculo dos índices desejados. Em primeiro lugar, há firmas cujos dados apresentam uma interrupção no tempo, não havendo nenhuma informação sobre a razão dessas interrupções (interrupção real de atividades ou simples interrupção na entrega dos formulários da RAIS). Para aquelas interrupções que duraram mais do que dois anos, considerou-se que a firma destruiu empregos e os recriou posteriormente. Porém, aquelas interrupções que duraram menos que dois anos foram consideradas erros. As firmas que apresentaram esse erro foram retiradas da amostra. Esse procedimento foi o mesmo adotado em Corseuil et al. (2002a), o qual foi recomendado pela equipe técnica do Ministério do Trabalho.

Em segundo, há casos em que as informações sobre o estoque de trabalhadores ao final de cada ano não são consistentes com as informações sobre as admissões e desligamentos ocorridos em cada ano. Nesses casos, confiou-se nos dados de estoque, somando adequadamente o resíduo às admissões ou aos desligamentos. Mais uma vez o procedimento adotado foi o mesmo usado em Corseuil et al. (2002a). Porém neste estudo optou-se por excluir as firmas para as quais os erros eram muito grandes (acima de 20 por cento do emprego médio da firma no período).

A Tabela 2 mostra o balanceamento do painel de dados com o qual foi realizado este trabalho empírico. Esta indica um alto índice de mortalidade de firmas, pois a maioria das firmas da amostra permaneceu em atividade ininterrupta por menos de quatro anos.

A Tabela 3 apresenta informações sobre o tamanho da amostra, tanto em termos do número de firmas quanto em termos do número médio de empregados em cada ano. Essas informações indicam, conforme esperado, uma contração da indústria na Região Metropolitana de São Paulo no período investigado, com redução tanto do emprego formal quanto do número de firmas. 
Table 2: Painel balanceamento

\begin{tabular}{|c|c|c|c|c|c|c|c|c|c|}
\hline Frequência & 1 & 2 & 3 & 4 & 5 & 6 & 7 & 8 & Total \\
\hline $\mathrm{N}^{\circ}$ de vezes & 10123 & 6606 & 4869 & 2310 & 1903 & 1070 & 880 & 4819 & 32580 \\
\hline
\end{tabular}

Table 3: Tamanho amostral por ano

\begin{tabular}{|l|c|c|c|c|c|c|c|c|}
\hline & 91 & 92 & 93 & 94 & 95 & 96 & 97 & 98 \\
\hline $\mathrm{N}^{\text {o de firmas }}$ & 16593 & 14265 & 13130 & 12077 & 12930 & 12618 & 13212 & 13004 \\
\hline Emprego total & 420,573 & 374,864 & 341,278 & 317,025 & 306,283 & 279,596 & 249,240 & 225,722 \\
\hline
\end{tabular}

A Figura 1 descreve a evolução, no período 1991-1998, das médias das taxas de labor churning especificadas na seção anterior, correspondentes às equações 9, 10 e 11: rotatividade da mão-de-obra da firma $i$ em $t$ (ou labor churning da firma $i$ em $t$ ), $R_{i t}$; rotatividade involuntária da firma $i$ em $t$ (ou churning involuntário da firma $i$ em $t$ ), $R I_{i t}$; e rotatividade involuntária líquida da firma $i$ em $t$ (ou churning involuntário líquido da firma $i$ em $t$ ), $R I L_{i t}$. Para cada ano, foram calculadas médias ponderadas, em que o peso de cada firma é dado pelo número médio de empregados de cada firma no ano. Na Figura 2 observa-se a evolução da taxa média de rotatividade involuntária líquida, por faixas de tamanho de firma. As faixas são: microempresas (até 19 empregados), pequenas empresas (entre 20 e 99 empregados), médias empresas (entre 100 e 499 empregados) e grandes empresas (acima de 500 empregados). Para fazer a classificação utilizou-se a medida do tamanho médio de longo prazo, em que o tamanho médio da firma é definido levando-se em conta todo o período observado. A figura revela que a evolução do labor churning é muito semelhante para as diferentes faixas de tamanho de firma, sugerindo fortemente que mudanças no ambiente macroeconômico afetam a rotatividade de forma semelhante em firmas com características diferentes ${ }^{13}$. Além disso, a figura revela um menor nível médio de rotatividade para as firmas maiores, conforme previsto por modelos da área de teoria das organizações. ${ }^{14}$

Na Figura 3 observa-se mais uma vez a evolução da taxa média de rotatividade involuntária líquida, porém agora desagregada para os 13 grandes subsetores da indústria. Novamente observa-se que a evolução do labor churning é bastante semelhante para firmas com características diferentes, reforçando a idéia de que há mudanças no ambiente macroeconômico que afetam a rotatividade de forma semelhante nas diferentes firmas. O subsetor de extrativismo mineral, que tem a menor rotatividade em média, é o que tem trajetória mais diferente das demais.

\section{O MODELO ECONOMÉTRICO E OS RESULTADOS OBTIDOS}

Com o objetivo de testar a hipótese principal do modelo teórico exposto na primeira seção (de firmas usando o churning como instrumento para reduzir salários), a seguinte equação foi estimada:

$$
\begin{aligned}
R I L_{i t}=\beta_{0}+\beta_{1}(\text { desemp } & \left.- \text { aberto }_{t}\right)+\beta_{2}\left(\text { lemprego }- \text { formal }_{t}\right) \\
& +\beta_{3} \text { inflacao }_{t}+\beta_{4} \text { pos }_{t}+\beta_{5}\left(\text { var }- \text { salarial }_{i t}\right)+\beta_{6} Z i t+u_{i t}
\end{aligned}
$$

em que $R I L_{i t}$ é a taxa de rotatividade involuntária líquida da mão-de-obra da firma $i$ no ano $t$ (ou taxa de churning involuntário líquido da firma $i$ em $t$ ), definida pela equação 11 da seção 3; desemp-aberto $t$

\footnotetext{
${ }^{13}$ Para as grandes empresas, a tendência da rotatividade no período 1996-1998 difere das demais

${ }^{14}$ Ver, por exemplo, Pfeffer and Cohen (1984) e Williamson (1985).
} 
Figure 1: Labor churning

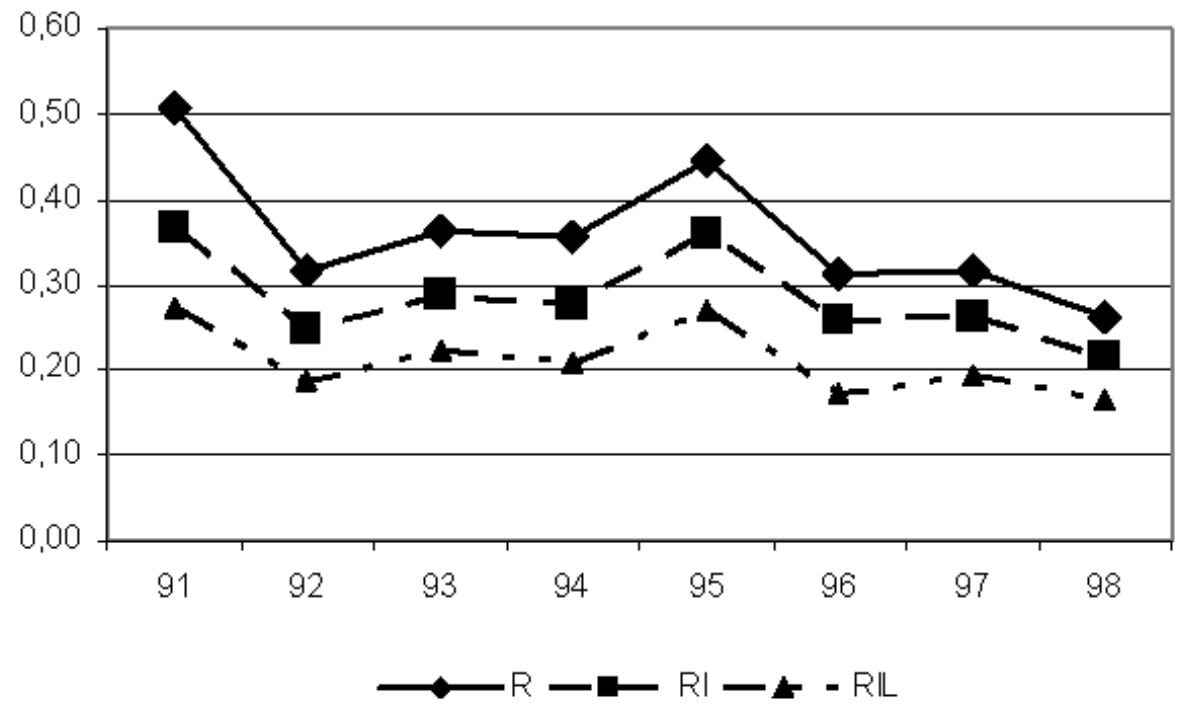

Figure 2: Rotatividade por tamanhos de firma

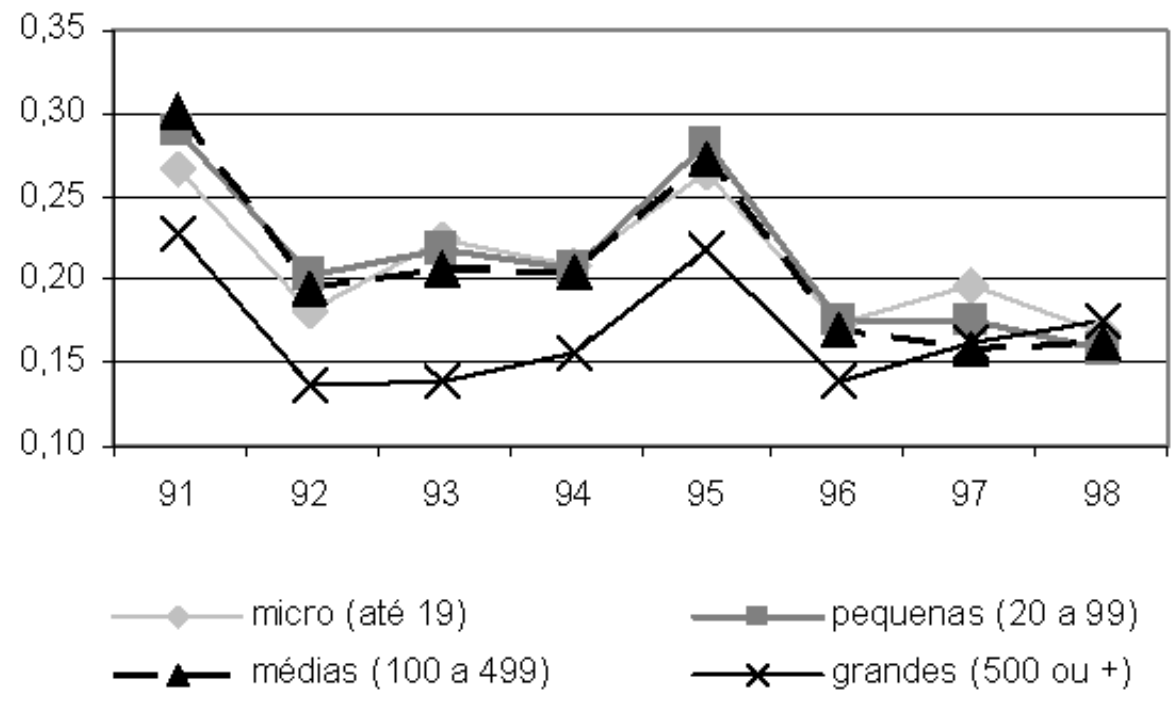


Figure 3: Rotatividade desagregada
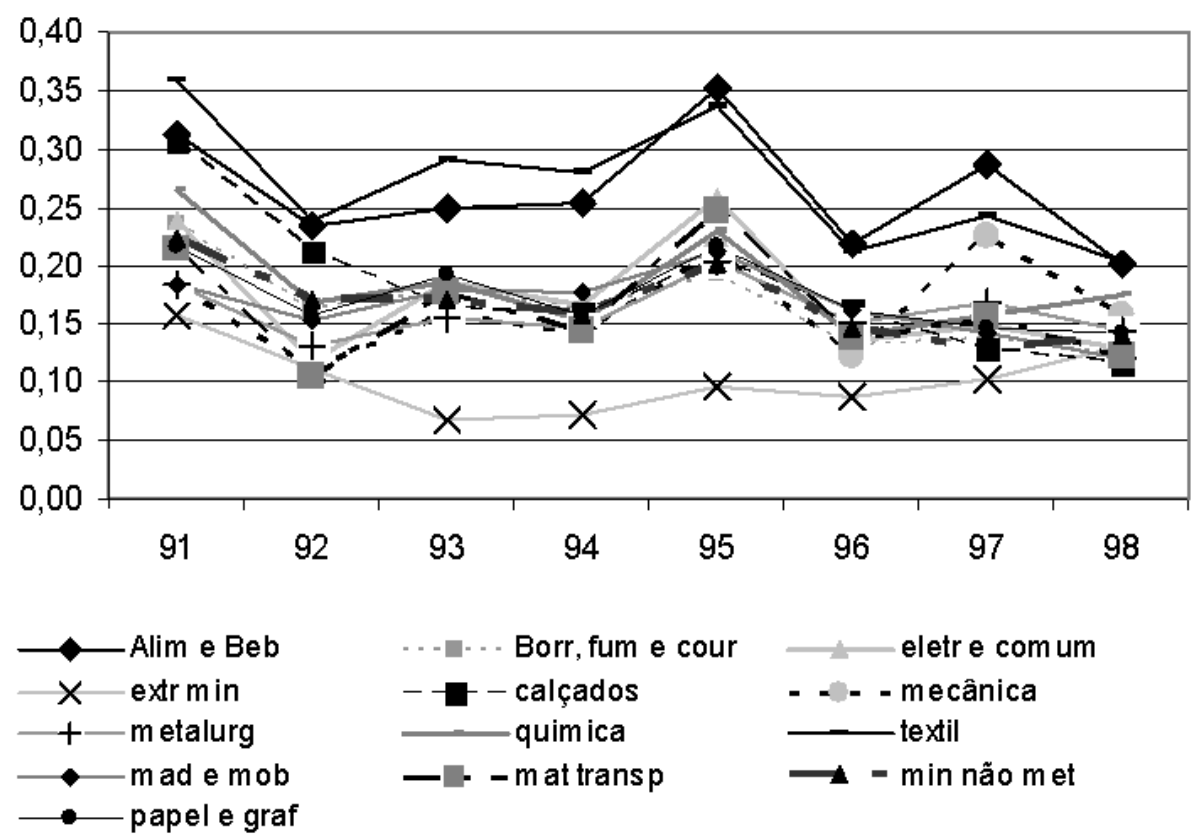

é a taxa média de desemprego aberto na Região Metropolitana de São Paulo no ano $t$, medida pela Fundação IBGE; lemprego-formal ${ }_{t}$ é o logarítmo do nível de emprego formal na Região Metropolitana de São Paulo em $t$, medido a partir dos dados da RAIS; in flacao $o_{t}$ é a taxa de inflação calculada a partir do índice de preços ao consumidor no ano $t$, calculado pelo IBGE; $p o s_{t}$ é uma variável dummy que assume o valor 1 para o período 1995-1999 (período pós plano real); $Z_{i t}$ corresponde a um vetor de variáveis de controle microeconômicas; e finalmente, var - salarial $l_{i t}$ é a variação da média dos salários reais dos empregados da firma $i$ entre $t-1$ e $t$, em que o cálculo foi feito usando o INPC. Vale lembrar que $R I L_{i t}$ mede o movimento de substituição de trabalhadores por iniciativa da firma, líquido daquela parcela de substituições que altera o perfil dos empregados em termos de nível de qualificação.

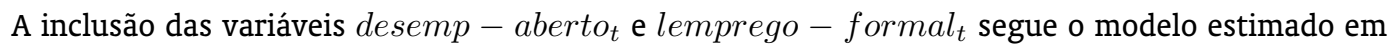
Orellano and Pazello (2006). Estas visam a controlar a relação positiva prevista pela teoria econômica entre a abundância de oportunidades de emprego e o churning. A inclusão desses controles é necessária mesmo que a variável $R I L_{i t}$ tenha sido construída usando apenas as demissões registradas como demissões por iniciativa da firma por dois motivos. O primeiro é que a informação oficial sobre a iniciativa das demissões no Brasil não é confiável. Muitas demissões voluntárias são registradas como demissões por iniciativa do empregador, para que os empregados possam retirar o FGTS. ${ }^{15}$ Assim sendo, a medida de churning utilizada neste trabalho ainda pode incluir um movimento de substituição de trabalhadores decorrente das demissões voluntárias. O outro motivo é que os modelos de matching

\footnotetext{
${ }^{15}$ Segundo dados do Suplemento Especial de Trabalho da PNAD de 1989, dentre os empregados formais do setor privado da Região Metropolitana de São Paulo que declararam ter pedido para sair de algum emprego entre setembro de 1987 e setembro de $1989,57,36$ por cento (\%) respondeu que recebeu o FGTS, o que indica a ocorrência de acordo para o registro como demissão por iniciativa da firma.
} 
também prevêm uma relação positiva entre a abundância de oportunidades de emprego e o churning, dado que em períodos de mais contratações tendem a ocorrer mais problemas com matchings.

A variável inflacao $_{t}$ foi incluída para controlar um possível efeito da inflação sobre a rotatividade da mão-de-obra. Como colocam (Cortez Reis and Camargo, 2005, p. 1), taxas de inflação mais elevadas tornam os salários reais mais flexíveis, facilitando a adaptação dos custos da firma à produtividade dos trabalhadores. Isso pode evitar ajustes através do emprego e pode implicar menor rotatividade, coeteris paribus.

A dummy $\operatorname{pos}_{t}$ visa a controlar possíveis efeitos que o plano real (e todas as mudanças que o acompanharam) possa ter tido sobre a rotatividade da mão-de-obra, além do efeito da estabilização já controlado pela taxa de inflação.

$Z i t$, o vetor de variáveis de controle desagregadas, é composto por: educação média defasada dos empregados de cada firma, também incluída em Orellano and Pazello (2006); e o tamanho médio defasado da firma. ${ }^{16}$

A variável $v a r-$ salarial $_{i t}$ é o foco de interesse deste estudo. Esta corresponde à diferença entre o salário real médio dos empregados da firma no ano $t$ e o salário real médio dos empregados da firma no ano $t-1$. Em cada ano, todos aqueles que estiveram empregados na firma são incluídos no cômputo, mesmo que tenham saído do emprego logo no primeiro semestre. Se var - salarial ${ }_{i t}$ for positiva, isso significa que, em média, o salário real foi maior no ano $t$ em comparação com o ano $t-1$. Porém isso não significa que o salário real médio dos empregados em dezembro do ano $t$ seja maior que o salário real médio dos empregados em dezembro do ano $t-1$.

Espera-se que, em resposta a uma variação positiva do salário real médio dos empregados da firma entre os anos $t-1$ e $t$, a firma substitua trabalhadores no ano $t$, aumentando o labor churning no ano $t$, desde que esse aumento do salário real médio não seja acompanhado de um aumento médio de produtividade.

Ocorre porém que a variável var - salarial $_{i t}$ é endógena, uma vez que a substituição de trabalhadores no ano $t$ (medida pela variável $R I L_{i t}$ ) afeta o salário real médio dos empregados da firma no ano $t$, afetando a variável var - salarial ${ }_{i t}$. Por esse motivo a equação 12 deve ser estimada em dois estágios.

Os instrumentos usados foram a variação real do salário mínimo entre $t-1$ e $t$ e a variação real do câmbio entre julho do ano $t-1$ e julho do ano $t$. Admite-se que a variação do salário mínimo em termos reais afeta a variação do salário real médio dos empregados formais pelo seu efeito direto sobre os que ganham um salário mínimo e pelo efeito conhecido como efeito numerário, em que o valor do salário mínimo funciona como um guia para a determinação dos salários de empregados que ganham mais do que o mínimo. Já a variação real da taxa de câmbio afeta a variação do salário real médio dos empregados formais através da alteração do poder de compra dos trabalhadores. Uma valorização real da taxa de câmbio torna mais baratos os produtos importados em moeda nacional, aumentando o salário real médio. Para que estes sejam instrumentos válidos, é necessário que a variação real do salário mínimo e a variação real do câmbio afetem o churning da mão-de-obra das firmas apenas através de seu efeito sobre a variação do salário real médio dos empregados. Testes para a validade dos instrumentos foram realizados e incluídos na tabela de resultados. ${ }^{17}$

\footnotetext{
${ }^{16}$ Também foi testada uma especificação incluindo as interações ano versus setor de atividade como controles. Foi usada a classificação de atividades econômicas de dois dígitos do IBGE, em que a indústria é dividida em quatorze subsetores. Essa especificação apresenta problemas de multicolinearidade, portanto várias das interações são excluídas automaticamente e os desvios padrão calculados tendem a ser sobre estimados.

${ }^{17}$ Também foram testadas especificações incluindo variáveis microeconômicas como instrumentos: tamanho defasado da firma e defasagem da variação do salário real médio (defasagem da variável instrumentalizada). A inclusão desses instrumentos não alterou o resultado esperado de que um aumento do salário real médio das firmas entre $t-1$ e $t$ implica um aumento da rotatividade da mão-de-obra em $t$. Na estimação que inclui apenas a defasagem do tamanho como IV, o efeito positivo da variação do salário real sobre a rotatividade foi sempre estatisticamente significativo. Na estimação que acrescenta a defasagem da variação salarial como IV, esse efeito positivo perde significância apenas em estimações feitas separadamente para algumas
} 
A regressão estimada no primeiro estágio foi:

$$
\begin{aligned}
\left(\text { var }_{-} \text {salarial }_{i t}\right)= & \alpha_{0}+\alpha_{1}\left(\text { var }- \text { salminimo }_{t}\right)+ \\
+ & \alpha_{2}\left(\text { var }- \text { cambial }_{t}\right) \\
& +\alpha_{3}\left(\text { desemp }- \text { aberto }_{t}\right)+\alpha_{4}\left(\text { lemprego }- \text { formal }_{t}\right) \\
& +\alpha_{5} \text { inflação }_{t}+\alpha_{6} \text { pos }_{t}+\alpha_{7} Z_{i t}+e_{i t}
\end{aligned}
$$

em que var - salminimo $o_{t}$ é a variação do salário mínimo real médio entre os anos $t-1$ e $t$ e var cambial $_{t}$ é a variação da taxa de câmbio em termos reais entre maio do ano $t-1$ e maio do ano $t$. Para o cálculo do salário mínimo real foi usada a série mensal do IPEA. Para a variação cambial entre o ano $t-1$ e o ano $t$ usou-se a taxa de câmbio real efetiva (INPC - exp. manuf.) de maio de cada ano. As demais covariadas correspondem aos controles da equação principal.

\subsection{Resultados}

O modelo econométrico proposto foi estimado não apenas para a totalidade da amostra, mas também separadamente para os quatro grupos de firmas divididos por faixas de tamanho. Assim como $n$ Figura 2 da seção 4, as faixas são:

1) microempresas (até 19 empregados),

2) pequenas empresas (entre 20 e 99 empregados),

3) médias empresas (entre 100 e 499 empregados) e

4) grandes empresas (acima de 500 empregados).

Como anteriormente, utilizou-se a medida do tamanho médio de longo-prazo para a classificação. Isso foi feito seguindo Orellano and Pazello (2006), porque a variável dependente deste estudo (o labor churning da firma) apresenta variância decrescente a medida que o tamanho da firma aumenta. ${ }^{18}$

As duas equações (primeiro e segundo estágios) foram estimadas em primeira diferença, pois os testes de Hausman indicaram a presença de um efeito fixo não observado correlacionado com as demais variáveis explicativas. A estimação das equações em nível, ou pelo modelo de efeitos aleatórios, não resultaria em estimadores consistentes dos parâmetros.

A Tabela 4 resume os resultados das estimações para o primeiro estágio.

As variáveis usadas como instrumentos são estatisticamente significativas em todas as regressões. Além disso, estas apresentam sempre o sinal esperado. Isto é, uma variação positiva do salário mínimo em termos reais afeta positivamente a variação do salário real médio dos empregados formais das firmas. Já a variação do câmbio real tem efeito negativo sobre a variação do salário real médio, com aumentos de salário real médio associados aos períodos de valorização cambial. Em relação aos controles, pode-se perceber que a variável tamanho médio das firmas defasado não é significativa em nenhuma das especificações. enquanto que a educação média defasada afeta negativamente a variação do salário real médio dos empregados formais das firmas.

A Tabela 5 resume os resultados do segundo estágio.

\footnotetext{
faixas de tamanho das firmas. No que se refere aos testes de sobre identificação, a estatística $J$ de Hansen aponta a validade dos instrumentos apenas para o caso do tamanho defasado da firma e apenas para as faixas de tamanho referentes a firmas pequenas, médias e grandes. Por esse motivo foi feita a opção de apresentar neste artigo apenas os resultados usando variação do salário mínimo real e variação da taxa real de câmbio como instrumentos.

${ }^{18}$ Como pode ser visto em (Orellano and Pazello, 2006, p. 201), o desvio padrão da taxa líquida de churning da mão-de-obra no período 1991-1998 vai de 1,1148 para firmas com até 4 empregados até 0,1856 para firmas com 500 empregados ou mais.
} 
Table 4: Resultados primeiro estágio

\begin{tabular}{|c|c|c|c|c|c|}
\hline \multicolumn{6}{|c|}{ Painel A: Instrumentos: Variação salário mínimo e variação da taxa de câmbio } \\
\hline Dep:var - salarial & Todas & micro & pequenas & média & grandes \\
\hline \multirow[t]{2}{*}{$v a r-c a m b i a l_{t}$} & $-5.81^{* * * *}$ & $-6.23^{* * * *}$ & $-4.04^{* * * *}$ & $-5.64^{* * *}$ & $-10.18^{*}$ \\
\hline & $(0.67)$ & $(0.84)$ & $(0.94)$ & (1.85) & (5.75) \\
\hline \multirow{2}{*}{ var - salminimo $t$} & $1.14^{* * *}$ & $0.74^{* * *}$ & $2.07^{* * * *}$ & $3.17^{* * *}$ & $4.49^{* * *}$ \\
\hline & (0.14) & $(0.17)$ & $(0.20)$ & $(0.43)$ & (1.16) \\
\hline \multirow[t]{2}{*}{ lemprego - formal } & 14.06 & 5.62 & 44.53 & 52.52 & -71.38 \\
\hline & (20.48) & (25.47) & (31.07) & $(82.7)$ & (71.87) \\
\hline \multirow[t]{2}{*}{ desemp-aberto } & -0.05 & 2.89 & $-13.08^{* * *}$ & -6.66 & 25.6 \\
\hline & $(4.44)$ & (5.45) & $(6.31)$ & (12.53) & $(44.6)$ \\
\hline \multirow[t]{2}{*}{ inflacao } & $-0.025^{* * *}$ & $-0.025^{* * *}$ & $-0.025^{* * *}$ & $-0.04^{* * *}$ & $-0.05^{* * * *}$ \\
\hline & $(0.003)$ & $(0.004)$ & $(0.004)$ & $(0.01)$ & $(0.02)$ \\
\hline \multirow[t]{2}{*}{ pos } & -9.68 & 5.5 & $-43.31^{* * *}$ & $140.5^{* * *}$ & $-178.21^{*}$ \\
\hline & (13.32) & (16.75) & $(20.02)$ & $(46.82)$ & $(107.24)$ \\
\hline \multirow[t]{2}{*}{ cons } & 2.52 & 0.15 & $12.38^{* * *}$ & 15.94 & -7.74 \\
\hline & $(4.51)$ & (5.65) & $(6.13)$ & (11.69) & (33.29) \\
\hline$N$ & 63310 & 47428 & 12306 & 3007 & 569 \\
\hline$F(6, N-7)$ & $113.67^{\text {*** }}$ & $59.13^{* * *}$ & $69.38^{* * * *}$ & $20.15^{* * *}$ & $10.61^{* * *}$ \\
\hline \multicolumn{6}{|c|}{ Painel B: Defasagem da educação dos trabalhadores como controle } \\
\hline \multirow[t]{2}{*}{$v a r-$ cambial $_{t}$} & $-6.27^{* * * *}$ & $-6.72^{* * *}$ & $-4.33^{* * *}$ & $-5.83^{* * *}$ & $-12.37^{* *}$ \\
\hline & $(0.68)$ & $(0.85)$ & $(0.94)$ & (1.86) & (5.73) \\
\hline \multirow[t]{2}{*}{ var - salminimot } & $1.06^{* * *}$ & $0.647^{* * *}$ & $2.040^{* * * *}$ & $3.13^{* * *}$ & $4.14^{* * *}$ \\
\hline & (0.139) & $(0.17)$ & $(0.20)$ & $(0.43)$ & $(1.14)$ \\
\hline \multirow[t]{2}{*}{$E d u c-$ media $_{t-1}$} & $-13.87^{* * *}$ & $-13.90^{* * *}$ & $-12.15^{* * *}$ & -7.94 & $-80.34^{* * *}$ \\
\hline & $(2.28)$ & (2.55) & (3.50) & $(20.00)$ & $(28.21)$ \\
\hline \multirow[t]{2}{*}{ lemprego - formal } & 11.12 & 1.55 & 44.29 & 53.42 & -64.31 \\
\hline & (20.55) & (25.61) & (31.09) & (82.65) & (69.67) \\
\hline \multirow[t]{2}{*}{ desemp-aberto } & 3.03 & 6.25 & $-11.08^{*}$ & -5.31 & 41.35 \\
\hline & (4.50) & (5.52) & $(6.33)$ & (82.65) & $(44.62)$ \\
\hline \multirow{2}{*}{ inflacao } & $-0.026^{* * * *}$ & $-0.026^{* * *}$ & $-0.025^{* * *}$ & $-0.04^{* * *}$ & $-0.052^{* *}$ \\
\hline & $(0.003)$ & $(0.003)$ & $(0.004)$ & $(0.01)$ & $(0.02)$ \\
\hline \multirow[t]{2}{*}{ pos } & $-3.66^{* * *}$ & 12.45 & $-39.96^{* *}$ & $-138.04^{* * *}$ & -147.80 \\
\hline & (13.37) & (16.82) & $(20.07)$ & $(47.82)$ & (105.18) \\
\hline \multirow[t]{2}{*}{ cons } & 1.05 & -1.75 & $12.09^{* *}$ & 15.82 & -3.55 \\
\hline & $(4.56)$ & $(5.73)$ & $(6.15)$ & $(11.63)$ & $(32.24)$ \\
\hline$N$ & 62813 & 46971 & 12268 & 3005 & 569 \\
\hline$F(7, N-8)$ & $131.66^{* * *}$ & $65.37^{* * *}$ & $92.85^{* * * *}$ & $39.86^{* * *}$ & $12.86^{* * * *}$ \\
\hline
\end{tabular}

\begin{tabular}{|c|c|c|c|c|c|}
\hline \multicolumn{6}{|c|}{ Painel C: Defasagens da educação dos trabalhadores e tamanho da firma como controles } \\
\hline$v a r-$ cambial $_{t}$ & $\begin{array}{r}-5.23^{* * *} \\
(0.65)\end{array}$ & $\begin{array}{r}-5.39^{* * * *} \\
(0.83)\end{array}$ & $\begin{array}{r}-4.17^{* * *} \\
(0.95)\end{array}$ & $\begin{array}{r}-5.73^{* * *} \\
(1.92)\end{array}$ & $\begin{array}{r}-11.41^{*} \\
(6.21)\end{array}$ \\
\hline var - salminimo $t$ & $\begin{array}{r}1.48^{* * *} \\
(0.19)\end{array}$ & $\begin{array}{r}1.16^{* * *} \\
(0.24)\end{array}$ & $\begin{array}{r}2.03^{* * * *} \\
(0.28)\end{array}$ & $\begin{array}{r}2.84^{* * * *} \\
(0.54)\end{array}$ & $\begin{array}{r}4.373^{* * *} \\
(1.63)\end{array}$ \\
\hline$E d u c-$ media $_{t-1}$ & $\begin{array}{r}-7.11^{* * *} \\
(2.33)\end{array}$ & $\begin{array}{r}-6.62^{* *} \\
(2.64)\end{array}$ & $\begin{array}{r}-8.81^{* *} \\
(3.74)\end{array}$ & $\begin{array}{r}-1.14 \\
(20.50)\end{array}$ & $\begin{array}{r}-64.36^{* *} \\
(30.25)\end{array}$ \\
\hline Tam - medio $t-1$ & $\begin{array}{r}0.18 \\
(0.12)\end{array}$ & $\begin{array}{r}0.87 \\
(2.04)\end{array}$ & $\begin{array}{r}0.05 \\
(0.59)\end{array}$ & $\begin{array}{r}0.21 \\
(0.28)\end{array}$ & $\begin{array}{r}0.10 \\
(0.12)\end{array}$ \\
\hline lemprego - formal & $\begin{array}{r}30.34 \\
(21.29)\end{array}$ & $\begin{array}{r}25.35 \\
(26.85)\end{array}$ & $\begin{array}{r}47.93 \\
(32.44)\end{array}$ & $\begin{array}{r}79.68 \\
(85.37)\end{array}$ & $\begin{array}{r}-60.65 \\
(71.74)\end{array}$ \\
\hline desemp - aberto & $\begin{array}{r}-2.47 \\
(4.39)\end{array}$ & $\begin{array}{l}-0.15 \\
(5.50)\end{array}$ & $\begin{array}{r}-12.20 \\
(6.32)\end{array}$ & $\begin{array}{r}-4.12 \\
(13.97)\end{array}$ & $\begin{array}{r}32.66 \\
(48.25)\end{array}$ \\
\hline inflacao & $\begin{array}{l}-0.02^{* * *} \\
(0.003)\end{array}$ & $\begin{array}{l}-0.03^{* * *} \\
(0.004)\end{array}$ & $\begin{array}{l}-0.02^{* *} \\
(0.004)\end{array}$ & $\begin{array}{r}-0.04^{* * *} \\
(0.01)\end{array}$ & $\begin{array}{r}-0.05^{* *} \\
(0.02)\end{array}$ \\
\hline pos & $\begin{array}{r}-25.54 \\
(17.87)\end{array}$ & $\begin{array}{l}-13.38 \\
(22.94)\end{array}$ & $\begin{array}{l}-34.95 \\
(27.09)\end{array}$ & $\begin{array}{r}-117.84^{* *} \\
(55.77)\end{array}$ & $\begin{array}{l}-173.33 \\
(152.51)\end{array}$ \\
\hline cons & $\begin{array}{l}8.78^{*} \\
(5.04)\end{array}$ & $\begin{array}{r}9.38 \\
(6.46)\end{array}$ & $\begin{array}{r}8.91 \\
(7.40)\end{array}$ & $\begin{array}{r}7.58 \\
(12.76)\end{array}$ & $\begin{array}{r}6.71 \\
(35.78)\end{array}$ \\
\hline $\begin{array}{l}N \\
F(8, N-9)\end{array}$ & $\begin{array}{r}45387 \\
77.81^{* * *}\end{array}$ & $\begin{array}{r}32791 \\
65.37^{* * * *}\end{array}$ & $\begin{array}{r}9692 \\
47.63^{* * *}\end{array}$ & $\begin{array}{r}2444 \\
12.02^{* * * *}\end{array}$ & $\begin{array}{r}460 \\
7.12^{* * * 4}\end{array}$ \\
\hline
\end{tabular}

***, ${ }^{* *},{ }^{*}$ significante a $1 \%, 5 \%$ e $10 \%$ respectivamente.

Erro padrão robusto em parênteses. 
Table 5: Resultados segundo estágio: Dependente: Rotatividade líquida

\begin{tabular}{|c|c|c|c|c|c|}
\hline \multicolumn{6}{|c|}{ Painel A: Instrumentos: Variação salário mínimo e variação da taxa de câmbio } \\
\hline Dep: $\operatorname{Rot}-\mathrm{liq}$ & Todas & micro & pequenas & média & grandes \\
\hline \multirow[t]{2}{*}{ var-salarial $t$} & $0.0002^{* * *}$ & $0.00015^{*}$ & $0.00019^{* * *}$ & 0.00006 & 0.000015 \\
\hline & $(0.00005)$ & $(0.00008)$ & $(0.00005)$ & $(0.00005)$ & $(0.00006)$ \\
\hline \multirow[t]{2}{*}{ lemp - formal } & 0.006 & 0.005 & -0.0013 & 0.016 & 0.000015 \\
\hline & $(0.016)$ & $(0.02)$ & $(0.02)$ & $(0.028)$ & $(0.03)$ \\
\hline \multirow[t]{2}{*}{ desemp - aberto } & $-0.031^{* * *}$ & $-0.032^{* * *}$ & $-0.030^{* * *}$ & $-0.029^{* * *}$ & $-0.025^{* * *}$ \\
\hline & $(0.002)$ & $(0.003)$ & $(0.003)$ & $(0.004)$ & (0.005) \\
\hline \multirow[t]{2}{*}{ inflacao } & 0.000000 & 0.000002 & -0.000003 & $-0.000006^{*}$ & $-0.000015^{* * *}$ \\
\hline & $(0.000003)$ & $(0.000004)$ & $(0.000002)$ & $(0.000003)$ & $(0.000005)$ \\
\hline \multirow[t]{2}{*}{ pos } & 0.017 & 0.004 & $0.055^{* * *}$ & $0.063^{* * *}$ & $0.066^{* * *}$ \\
\hline & (0.013) & (0.019) & $(0.012)$ & $(0.014)$ & $(0.024)$ \\
\hline \multirow[t]{2}{*}{ cons } & $-0.018^{* * * *}$ & $-0.015^{* * * *}$ & $-0.029^{* * *}$ & $-0.2413^{* * * *}$ & $-0.15^{* * *}$ \\
\hline & $(0.003)$ & $(0.004)$ & $(0.002)$ & $(0.0037)$ & $(0.006)$ \\
\hline$N$ & 63310 & 47428 & 12306 & 3007 & 569 \\
\hline HansenJ & 0.672 & 1.645 & 1.532 & 13.448 & 0.406 \\
\hline$P$-value & 0.4124 & 0.1996 & 0.2158 & 0.0002 & 0.5240 \\
\hline \multicolumn{6}{|c|}{ Painel B: Defasagem da educação dos trabalhadores como controle } \\
\hline \multirow{2}{*}{$v_{a r}-$ salarial $_{t}$} & $0.00016^{* * *}$ & $0.00014^{*}$ & $0.00018^{* * *}$ & 0.000059 & 0.000017 \\
\hline & $(0.000)$ & $(0.000)$ & $(0.000)$ & $(0.000)$ & $(0.000066)$ \\
\hline \multirow[t]{2}{*}{$E d u c-$ media $_{t-1}$} & $0.007^{* * *}$ & $0.006^{* *}$ & $0.016^{* * * *}$ & $0.013^{* * *}$ & 0.010 \\
\hline & $(0.002)$ & $(0.002)$ & $(0.002)$ & $(0.004)$ & $(0.008)$ \\
\hline \multirow[t]{2}{*}{ pos } & 0.019 & 0.007 & $0.055^{* * *}$ & $0.061^{* * *}$ & $0.064^{* * *}$ \\
\hline & $(0.014)$ & $(0.019)$ & $(0.012)$ & $(0.014)$ & $(0.024)$ \\
\hline \multirow[t]{2}{*}{ inflacao } & 0.000 & 0.000 & -0.000 & $-0.000^{*}$ & $-0.000^{* * * *}$ \\
\hline & $(0.000)$ & $(0.000)$ & $(0.000)$ & $(0.000)$ & $(0.000)$ \\
\hline \multirow{2}{*}{ desemp - aberto } & $-0.031^{\text {**** }}$ & $-0.032^{* * *}$ & $-0.031^{* * *}$ & $-0.030^{* * * *}$ & $-0.026^{* * * *}$ \\
\hline & $(0.003)$ & $(0.003)$ & $(0.003)$ & $(0.004)$ & $(0.007)$ \\
\hline \multirow[t]{2}{*}{ lemp - formal } & 0.010 & 0.009 & -0.000 & 0.013 & 0.008 \\
\hline & (0.016) & $(0.021)$ & $(0.020)$ & $(0.028)$ & $(0.030)$ \\
\hline \multirow[t]{2}{*}{ cons } & $-0.019^{* * * *}$ & $-0.016^{* * *}$ & $-0.030^{* * *}$ & $-0.026^{* * *}$ & $-0.017^{* * * *}$ \\
\hline & $(0.003)$ & $(0.004)$ & $(0.003)$ & $(0.004)$ & $(0.006)$ \\
\hline$N$ & 62,813 & 46,971 & 12,268 & 3,005 & 569 \\
\hline HansenJ & 1.09 & 1.90 & 0.31 & 10.66 & 0.23 \\
\hline$P$-value & 0.30 & 0.17 & 0.58 & 0.00 & 0.63 \\
\hline \multicolumn{6}{|c|}{ Painel C: Defasagens da educação dos trabalhadores e tamanho da firma como controles } \\
\hline \multirow[t]{2}{*}{ var - salarial $_{t}$} & $0.001^{\text {**** }}$ & $0.001^{* * *}$ & $0.001^{\text {**** }}$ & $0.001^{* * *}$ & $0.000^{* *}$ \\
\hline & $(0.000)$ & $(0.000)$ & $(0.000)$ & $(0.000)$ & $(0.000)$ \\
\hline \multirow{2}{*}{ Tamanho $_{t-1}$} & -0.000 & -0.002 & -0.000 & -0.000 & -0.000 \\
\hline & $(0.000)$ & $(0.002)$ & $(0.001)$ & $(0.000)$ & $(0.000)$ \\
\hline \multirow[t]{2}{*}{$E d u c-$ media $_{t-1}$} & $0.006^{* *}$ & 0.003 & $0.017^{* * *}$ & 0.009 & $0.026^{*}$ \\
\hline & $(0.003)$ & $(0.003)$ & $(0.004)$ & $(0.012)$ & $(0.014)$ \\
\hline pos & $-0.056^{\text {**** }}$ & $-0.060^{* * * *}$ & $-0.053^{* *}$ & -0.026 & -0.003 \\
\hline & $(0.017)$ & $(0.023)$ & $(0.022)$ & $(0.030)$ & $(0.044)$ \\
\hline inflacao & $0.000^{* * *}$ & $0.000^{*}$ & $0.000^{*}$ & 0.000 & -0.000 \\
\hline & $(0.000)$ & $(0.000)$ & $(0.000)$ & $(0.000)$ & $(0.000)$ \\
\hline desemp-aberto & $-0.018^{* * *}$ & $-0.019^{* * *}$ & $-0.012^{* *}$ & $-0.013^{*}$ & -0.014 \\
\hline & $(0.003)$ & $(0.004)$ & $(0.005)$ & $(0.008)$ & $(0.011)$ \\
\hline lemp - formal & -0.031 & -0.024 & $-0.067^{* *}$ & -0.056 & 0.035 \\
\hline & $(0.021)$ & $(0.026)$ & $(0.033)$ & $(0.061)$ & $(0.038)$ \\
\hline cons & -0.002 & -0.001 & $-0.010^{* * *}$ & 0.002 & -0.001 \\
\hline & $(0.004)$ & $(0.005)$ & $(0.005)$ & $(0.007)$ & $(0.011)$ \\
\hline$N$ & 45,387 & 32,791 & 9,692 & 2,444 & 460 \\
\hline HansenJ & 12.48 & 79.20 & 3.02 & 0.21 & 0.00 \\
\hline$P$-value & 0.00 & 0.00 & 0.08 & 0.64 & 0.98 \\
\hline
\end{tabular}

${ }^{* * *},{ }^{* *},{ }^{*}$ significante a $1 \%, 5 \%$ e $10 \%$ respectivamente.

Erro padrão robusto em parênteses.

Teste de Hausman rejeita a hipótese nula de que o efeito aleatório é consistente. 
O painel A apresenta os resultados da especificação que não inclui nenhuma variável desagregada como controle. O painel B diz respeito aos resultados incluindo a educação média defasada dos empregados da firma. Finalmente, o painel $\mathrm{C}$ inclui o tamanho defasado da firma. A última linha de cada painel da tabela apresenta a estatística Hansen $J$ para testar a validade dos instrumentos (e o $P$-value correspondente logo abaixo). Nos painéis A e B, o teste aponta que os instrumentos são válidos para o total da amostra e para todas as faixas de tamanho, exceto apenas a faixa $3 .{ }^{19}$ No painel $\mathrm{C}$, o teste aponta que os instrumentos são válidos para as faixas de tamanho 3 e 4.

Em todas as regressões os resultados indicam um efeito positivo da variação do salário real médio entre os anos $t-1$ e $t$ sobre a rotatividade involuntária líquida da mão-de-obra das firmas no ano $t .^{20}$ Nos painéis A e B, esse efeito é estatisticamente significativo para a totalidade da amostra e para as faixas de tamanho 1 e 2 . Já no painel $C$, o efeito é sempre estatisticamente significativo. Considerando a amostra como um todo no painel $\mathrm{A}$, uma variação de cem unidades monetárias reais no salário médio entre $t-1$ e $t$ implica um aumento de 2 pontos percentuais na taxa de rotatividade em média no período. Vale notar que os valores estão em reais de dezembro de 2006.

Para a taxa de desemprego, os resultados são sempre consistentes com aqueles já obtidos em Orellano and Pazello (2006). Maiores taxas de desemprego reduzem o labor churning. Isso ocorre não só pela redução da taxa de demissões voluntárias (que devem permanecer no cálculo da variável dependente devido aos incentivos existentes na legislação brasileira para que as demissões voluntárias sejam declaradas com demissões por iniciativa da firma), mas também porque períodos de menos contratações estão relacionados a menos problemas de matchings. O efeito marginal da taxa de desemprego sobre 0 labor churning é expressivo. No painel A, um aumento de um ponto percentual na taxa de desemprego aberto do ano implica em média uma queda de aproximadamente 3 pontos percentuais na taxa de labor churning desse ano. Observou-se ademais que, controlada a taxa de desemprego, as variações do nível de emprego formal na indústria não têm efeito significativo sobre o labor churning.

Observando a totalidade das regressões estimadas, não se pode dizer que o índice de inflação apresenta um efeito sobre a rotatividade sempre no mesmo sentido. Contudo, observando apenas as regressões cujo teste de Hansen aponta para a validade dos instrumentos, pode-se dizer que esse efeito, quando significativo, apresenta o sinal esperado, com níveis relativamente menores de rotatividade em anos que apresentaram maiores taxas de inflação. Nesse caso, há evidências de que salários reais mais flexíveis facilitam a adaptação dos custos da firma a produtividade dos trabalhadores, reduzindo o labor churning.

Controlado o efeito da estabilização da moeda e outros, os resultados apontam que as demais mudanças econômicas associadas ao período pós plano real tiveram um efeito de aumento do labor churning. Nos painéis A e B, o efeito da dummy pós é positivo e significativo para as faixas 2,3 e 4 . Apesar de que no painel $C$ o efeito estimado muda de sinal, este não é estatisticamente significativo para as faixas 3 e 4, em que o teste de Hansen aponta a validade dos instrumentos. No painel A, para a faixa 2, por exemplo, observa-se que a taxa de churning das firmas foi, em média, 5.5 pontos percentuais maior no período pós-plano real em comparação ao período anterior.

Finalmente, no que se refere às variáveis de controle desagregadas, observou-se um efeito positivo da educação média defasada dos empregados da firma sobre a rotatividade, ao contrário do que seria esperado. Já o tamanho médio defasado da firma nã apresenta efeito significativo.

\footnotetext{
${ }^{19}$ Reestimamos esta regressão para a faixa 3 considerando apenas um instrumento qual seja, a variação cambial ou a variação do salário mínimo. Os resultados sugerem que os instrumentos são significativos isoladamente e apresentam, bem como as outras variáveis de controle, o sinal esperado. Contudo a variação salarial somente possui efeito estatisticamente significativo no segundo estágio, quando se usa a variação cambial como instrumento. Os resultados estão disponíveis após solicitação.

${ }^{20}$ Os resultados se mantém quando a estimação leva em considerando efeitos de cluster. Os resultados estão à disposição mediante solicitação.
} 


\section{CONCLUSÕES}

Este artigo propõe um modelo para explicar o movimento de substituição de empregados (labor churning) nas indústrias no Brasil. Dados sobre a evolução do labor churning na década de 1990 para os empregados formais da indústria paulista revelam uma trajetória muito semelhante do churning para diferentes faixas de tamanho de firmas e para os diferentes subsetores da indústria, sugerindo que mudanças no ambiente macreconômico afetam o churning de forma semelhante em firmas com características diferentes. Os modelos de labor churning baseados em decisões de demissões voluntárias ou em teorias de matching não explicam totalmente essa evolução observada.

A hipótese principal do modelo proposto neste artigo é que as firmas, ao enfrentarem choques exógenos que elevam o salário real, substituem empregados com o objetivo de reduzir seus gastos com mão-de-obra, particularmente em momentos de baixa inflação, em que há maior rigidez dos salários reais.

Um estudo econométrico em dois estágios foi realizado usando os microdados da RAIS (Relação Anual de Informações Sociais) para o setor industrial da Região Metropolitana de São Paulo no período 1992-1998. No primeiro estágio foram encontradas evidências de que valorizações cambiais e aumentos reais do salário mínimo são choques que elevam o salário real médio dos trabalhadores formais. 0 segundo estágio corrobora a hipótese principal do modelo proposto, de firmas substituindo empregados para reduzir gastos com mão-de-obra quando ocorre um choque exógeno que eleva o valor real dos salários.

Conclui-se que a segmentação característica do mercado de trabalho brasileiro, entre setor formal e informal, combinada a políticas de aumento do salário mínimo real e ao efeito numerário que este pode exercer sobre os demais salários, ou combinada a períodos de valorização cambial, pode provocar um aumento da substituição de empregados formais para um nível acima do que seria o esperado como consequência de demissões voluntárias e de processos de matching.

\section{BIBLIOGRAPHY}

Amadeo, E., Camargo, J. M., Paes de Barros, R., Urani, A., Mendonça, R., \& Pero, V. (1993). Ajuste estrutural e flexibilidade do mercado de trabalho no Brasil. In Anais da ANPEC, pages 503-531. ANPEC.

Barron, J. M. \& McCafferty, S. (1977). Job search, labor supply and the quit decision: Theory and evidence. The American Economic Review, 67(4):683-691.

Botelho, F. \& Ponczek, V. (2007). Segmentation in the Brazilian labor market. Technical Report 164, EESP/FGV-SP.

Burgess, S., Lane, J., \& Stevens, D. (2000). Job flows, worker flows and churning. Journal of Labor Economics, 18(3):473-502.

Cacciamali, M. C. (1992). Mudanças estruturais e na regulação do mercado de trabalho no Brasil nos anos 80. Technical Report 6, IPE/USP.

Camargo, J. M., Neri, M., \& Gonzaga, G. (2001). Salário mínimo, efeito farol e pobreza. Revista de Economia Política, 21(2):78-90.

Corseuil, C. H., Ribeiro, E. P., Santos, D., \& Dias, R. (2002a). Criação, destruição e realocação de emprego no Brasil. Technical Report 855, IPEA.

Corseuil, C. H., Ribeiro, E. P., Santos, D., \& Servo, L. (2002b). Job and worker flows in Brazil. In MenezesFilho, N. A., editor, Labor Market Dynamics in Brazil, Final Report, Second Draft, Part I. Inter-American Development Bank Research Network, 11th Round, FIPE-USP. 
Cortez Reis, M. \& Camargo, J. M. (2005). Desemprego dos jovens no Brasil: Os efeitos da estabilização da inflação em um mercado de trabalho com escassez de informação. Texto para Discussão Interna 1116, PUC Rio de Janeiro.

Davis, S. J., Haltiwanger, J. C., \& Schuh, S. (1998). Job Creation and Destruction. The MIT Press.

Ehrenberg, R. \& Smith, R. (2000). A Moderna Economia do Trabalho: Teoria e Política Pública. Editora Makron Books, São Paulo.

Gonzaga, G. (1996). Rotatividade e qualidade do emprego no Brasil. Texto para Discussão Interna PUC, Rio de Janeiro.

Gonzaga, G. (2003). Labor turnover and labor legislation in Brazil. Texto para Discussão Interna 475, PUC, Rio de Janeiro.

Mincer, J. (1976). Unemployment effects of minimum wages. Journal of Political Economy, 84:87-104.

Nickell, S. J. (1978). Fixed costs, employment and labour demand over the cycle. Economica, 45:329-345.

Nickell, S. J. (1986). Dynamic models of labour demand. In Ashenfelter, O. \& Layard, R., editors, Handbook of Labor Economics, pages 473-522. North Holland, Amsterdam.

Nickell, S. J. (1995). Labour market dynamics in OECD countries. Discussion and Working Papers, Institute of Economics and Statistics, Oxford University.

Orellano, V. I. F. \& Pazello, E. T. (2006). Evolução e determinantes da rotatividade da mão-de-obra nas firmas da indústria paulista na década de 1990. Pesquisa e Planejamento Econômico, 36(1):179-207.

Pfeffer, J. \& Cohen, Y. (1984). Determinants of internal labor markets in organizations. Administrative Science Quarterly, 29(4):550-572.

Salop, S. C. (1979). A model of the natural rate of unemployment. American Economic Review, 69:117-125.

Stiglitz, J. E. (1974). Alternative theories of wage determination and unemployment in L.D.C.s: The labor turnover model. Quarterly Journal of Economics, 88(2):194-227.

Ulyssea, G. (2006). Informalidade no mercado de trabalho brasileiro: Uma resenha da literatura. Revista de Economia Política, 26(4):596-618.

Williamson, O. E. (1985). The Economic Institutions of Capitalism: Firms, Markets, Relational Contracting. The Free Press, New York. 